\title{
Interleukin-31 Serum And Pruritus Dimension After Acupuncture Treatment In Hemodialysis Patients: A Randomized Clinical Trial
}

\author{
Dedi Ardinata $^{1 *}$, Rozaimah Zain-Hamid² ${ }^{2}$ Irma. D. Roesyanto-Mahadi ${ }^{3}$, Hasan Mihardja ${ }^{4}$ \\ ${ }^{1}$ Department of Physiology, Faculty of Medicine, Universitas Sumatera Utara, Medan, Indonesia; ${ }^{2}$ Department of Pharmacology \\ and Therapeutics, Faculty of Medicine, Universitas Sumatera Utara, Medan, Indonesia; ${ }^{3}$ Department of Dermatology and \\ Venereology, Faculty of Medicine, Universitas Sumatera Utara, Medan, Indonesia; ${ }^{4}$ Department of Medical Acupuncture, \\ Faculty of Medicine, Universitas Indonesia, Jakarta, Indonesia
}

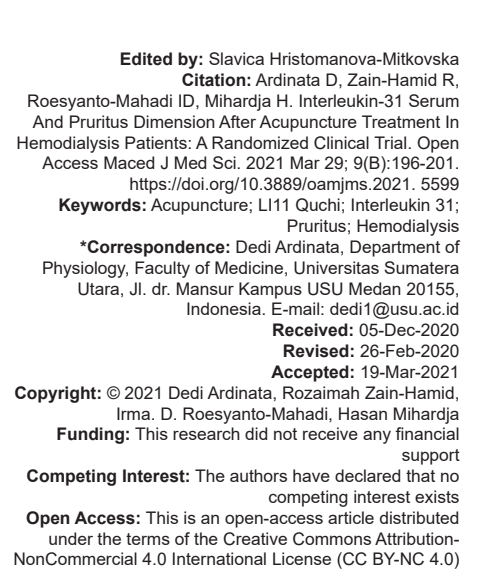

Introduction

Patients suffering from chronic kidney disease (CKD) who undergo hemodialysis show a tendency to experience pruritus with varying prevalence. Among the adult dialysis patients, the prevalence of CKD associated pruritus in each study ranged between $18 \%$ and $97.8 \%$ [1]; thus, Mathur et al. [2] found that pruritus are present in about $40-84 \%$ of patients with an endstage renal disease with variation in its distribution and severity [2]. CKD-related pruritus has a multifactorial etiopathogenesis associated with physical disability impaired quality of life and limitations in daily living activities [3], [4].

It noted that instruments for assessment of pruritus course are still uncommon. The 5-D itch scale has been developed as a short but multidimensional survey designed to help in clinical studies and claims to serve as a monitoring instrument for the long-term course of pruritus. Five dimensions include degree, duration, direction, disability, and distribution [5].
Cytokines Interleukin (IL)-31 mainly produced by Th- 2 cells act as pruritogenic whereas IL-31 serum levels in patients were significantly higher, undergoing hemodialysis with symptoms of pruritus, and there was a positive correlation of responses between IL-31 serum levels and pruritic intensity [6]. Pruritus therapy in chronic renal failure patients undergoing hemodialysis includes: Modification of dialysis techniques, topical treatment (emollient, aromatherapy, capsaicin cream, tacrolimus, and gamma-linolenic acid ointment), ultraviolet irradiation, a rubdown with Japanese dry towels, $\mu$-opioid receptor antagonists (naltrexone), $\kappa$-opioid receptor agonists (nalfurafine and butorphanol), thalidomide, pentoxifylline, gabapentin, and acupuncture [7], [8], [9].

The mechanism of action of acupuncture produces an anti-inflammatory effect by influencing the Th-1 and Th-2 balance [10]. Th-1 and Th-2 balance are affected by a $\beta$ endorphin secretion that occurs due to acupuncture [11], [12]. The antiinflammatory effect of acupuncture is to increase the levels of anti-inflammatory cytokines without lowering 
pro-inflammatory cytokines [13], [14]. Results from a systemic review show that acupuncture has a beneficial effect on pruritus patients undergoing hemodialysis [15]. Stimulation acupuncture point of the single LI11 Quchi for $1 \mathrm{~h}, 3$ times a week for 4 weeks, significantly reduce pruritus in hemodialysis patients [16], as well as unilateral acupuncture stimulation in LI11 Quchi for 1 h, 2 times a week, for 6 weeks, it significantly reduces pruritus in hemodialysis patients [17]. Several studies have reported the benefits of acupuncture for pruritus in hemodialysis patients, but the correlation with IL-31 serum levels has never been known. The purpose of this study was to demonstrate the impact of acupuncture in LI11 and IL-31 serum level and its correlation with dimensions of the pruritus in hemodialysis patients.

\section{Methods}

A randomized controlled trial (RCT) was carried between parallel groups August 2019 to December 2019 in the Hemodialysis Unit, Kidney, and Hypertension Installation of the $\mathrm{H}$. Adam Malik General Hospital, Medan, Indonesia (government hospital). The study compared one group receiving acupuncture in LI11 Quchi (intervention group) and the other receiving placebo (control group). The STRICTA (Standards for Reporting Interventions in Clinical Trials of Acupuncture) was thoroughly documented the treatment as extending the CONSORT statement [18].

It took sixty patients as subjects. It applied a consecutive sampling and they were set into two groups randomly with the help of the online application at https://www.randomizer.org/. One group received an acupuncture intervention, and another was as a control group received a placebo. The randomization procedure is performed by individuals who are not directly engaged in present studies or hired patient management. Criteria for inclusion are restricted to patients:

(1) Men and women over the age of 18 years; (2) those underwent routine hemodialysis 2 times a week for more than 6 months and in a stable hemodynamic state; (3) those who are with hemodialysis with polysulfane filters and bicarbonate solutions; (4) subjects with pruritus at least 6 weeks before acupuncture is taken; (5) those use drugs related to primary disease (CKD) and do not affect pruritus; (6) subjects who already stopped using of drugs that affect pruritus; and (7) subjects who never get acupuncture or at least the past 8 weeks did not get acupuncture; include;

On the other hand, the exclusion criteria

(1) Who are not ready to follow the research protocol entirely for various reasons; (2) those who are having allergic reactions to acupuncture needles;
(3) those have the infection skin of the punctured acupuncture needle; (4) being get treatment in intensive care for various reasons; (5) those who use drugs that may affect pruritus given; (6)who are suffer from atopic psoriasis and dermatitis during the observation period, and; (7) who have mental and physical circumstances that affect the ability to answer questionnaire questions.

The sample size was calculated using $G^{*} P o w e r$ 3.1.9.2 [19], with effect size $=0.8$; $\alpha$ err prob. $=0.05$ and Power (1- $\beta$ err prob.) $=0.90$, so in each group we need at least 28 subjects. Health Research Ethics Commission (KEPK) Faculty of Medicine, Universitas Sumatera Utara, and H. Adam Malik General Hospital, Medan, Indonesia, approved the trial protocol (455/TGL/ KEPK FK USU-RSUP HAM/2018). Thus, the Helsinki Declaration (Edinburgh Version 2000) principles were applied. The information of this study was socialized together with the consent approvement.

No changes were made in the dialysis procedure and drug use during the study, except for drugs that were pruritus affected. Before the intervention, the drugs usage was stopped until the end of the data collection for 7 days (washing period). We measured dimensional of the pruritus with the Indonesian language version of The 5-Ditch scale [20] for all research subjects and then complete information collection forms including subject characteristics and possible pruritus-influencing factors: Age, sex, significant diseases, body mass index after hemodialysis, quantitative c-reactive protein, duration of hemodialysis, urea reduction ratio, hemoglobin, dimensional, and scale of pruritus and IL-31 serum levels (baseline). After 6 weeks (end of the study period), dimensional of the pruritus and IL-31 serum levels was re-measured.

The Indonesian version of the 5-D itch scale [20] is a multidimensional quantitative evaluation of pruritus experienced by pruritus patients undergoing hemodialysis consisting of dimensions: Degree, duration, direction, disability, and distribution of itching obtained in response questionnaires of 1-5 for each dimension and 5-25 for the total score. A nurse who had been trained without knowing the subject was in the intervention or control group (blind) conducted an evaluation of the 5-D itch scale on all subjects.

Levels of IL-31 in serum were measured by a commercially available enzyme-linked immunosorbent assay kit (catalogue number EH0197, FineTest ${ }^{\circledR}$, Wuhan, Hubei, China), according to the manufacturer's instructions. The detection range: 7813-500 pg/ml. Precision: intra-assay: $C V<8 \%$, inter-assay: $C V<10 \%$. Specimens of the blood vein were taken before the procedure for hemodialysis was conducted. Subject blood vein specimens were taken before the hemodialysis procedure. Allow samples to clot at room temperature for 2 h or $4^{\circ} \mathrm{C}$ overnight before centrifuging at roughly $1000 \times \mathrm{G}$ for $20 \mathrm{~min}$. Collect the supernatant and immediately carry out the assay. The collection of blood could be disposable, non-pyrogenic, and non-endotoxin tubes and could be 
stored at $-40^{\circ} \mathrm{C}$ until the test. After $1 \mathrm{~h}$ of hemodialysis, if the hemodynamic status was stable, aseptic action was taken at the $2^{\text {nd }} \mathrm{h}$, and the antiseptic was provided at LI11 Quchi. The LI11 Quchi acupuncture point was located on the lateral side of the elbow, which is in the center connecting the LU5 end to the lateral humeral epicondyles. If the elbow joint is in maximum flexion, LI11 Quchi was located at the tip of the lateral elbow line fold [21]. All treatments were conducted twice a week for 6 weeks in the intervention group and the control group [17].

All data were analyzed using IBM Statistical Package for the Social Sciences (SPSS) Statistics version (IBM-SPSS Inc., Chicago, IL, USA). Normally distributed binary data are presented in mean, and standard deviation or abnormally distributed data have been shown in median (Me) and minimum-max (min-max), number (n) and percentage (percent) of categorical data. The paired t-test has been used to compare the normally distributed data with the matched group (in-group). The unpaired t-test was used to compare the normally distributed data with the unpaired group (for between-group). Mann-Whitney test for comparison of distributed data is not a standard and unpaired group (for between-group). Spearman's rho test was used for correlation of abnormally distributed data. Significance has been set at $p<0.05$.

\section{Results}

Data obtained showed the results of 30 subjects of intervention group and 30 of non accuppunture treatment. Those two data were analyzed according to the characteristics factors that influence pruritus. It noted that there were no significant differences in the characteristics of the subjects between the intervention group and the control group; this showed that the two study groups matched pairs to influence pruritus (Table 1).

Table 1: Characteristics of subjects

\begin{tabular}{|c|c|c|c|}
\hline Characteristics & Control $(n=30)$ & Total & $\mathrm{p}$ \\
\hline \multicolumn{4}{|l|}{ Sex, n (\%) } \\
\hline Male & $22(36.70)$ & $44(73.30)$ & $1.000^{\mathrm{a}}$ \\
\hline Female & $8(13.30)$ & $16(26.70)$ & \\
\hline Age (year), Me (min-max) & $54.50(25-77)$ & & $0.876^{\mathrm{b}}$ \\
\hline \multicolumn{4}{|l|}{ Major diseases, n (\%) } \\
\hline Hypertension & $11(18.30)$ & $26(43.30)$ & $0.508^{\mathrm{a}}$ \\
\hline Diabetic nephropathy & $11(18.30)$ & $21(35.00)$ & \\
\hline Infection and obstructive kidney disease & $8(13.30)$ & $13(21.70)$ & \\
\hline $\mathrm{BMI}$ after $\mathrm{HD}, \mathrm{Me}$ (min-max) & $23.54(17.69-28.13)$ & & $0.442^{\mathrm{b}}$ \\
\hline Quantitative CRP (mg/dl), Me (min-max) & $0.35(0.35-2.80)$ & & $0.648^{\mathrm{b}}$ \\
\hline Duration of hemodialysis (month), (mean $\pm \mathrm{SD}$ ) & $35.63 \pm 16.97$ & & $0.520^{\circ}$ \\
\hline URR (mean \pm SD) & $0.69 \pm 0.7$ & & $0.780^{\circ}$ \\
\hline Hemoglobin $(\mathrm{g} / \mathrm{dl})($ mean $\pm \mathrm{SD})$ & $9.52 \pm 1.38$ & & $0.551^{\mathrm{C}}$ \\
\hline Creatinine $(\mathrm{mg} / \mathrm{dl})($ mean $\pm \mathrm{SD})$ & $15.84 \pm 4.19$ & & $0.550^{\circ}$ \\
\hline$\|-31(\mathrm{pg} / \mathrm{ml})($ mean $\pm \mathrm{SD})$ & $36.27 \pm 29.31$ & & $0.965^{\mathrm{c}}$ \\
\hline \multicolumn{4}{|l|}{ Dimensional of the pruritus, Me (min-max) } \\
\hline Duration & $2(1-5)$ & & 0.502 \\
\hline Degree & $4(2-5)$ & & 0.792 \\
\hline Direction & $4(1-5)$ & & 0.064 \\
\hline Disability & $4(2-5)$ & & 0.496 \\
\hline Distribution & $3(1-5)$ & & 0.383 \\
\hline The total scale of pruritus (mean $\pm S D$ ) & $16.83 \pm 3.97$ & & $0.613^{\mathrm{c}}$ \\
\hline
\end{tabular}

It found the mean IL-31 serum levels after 6 weeks of acupuncture in LI11 Quchi did not significantly decrease in the subjects (Table 2). The results of the paired t-test showed that there was no significant decrease in the mean IL-31 serum levels before and after 6 weeks in the intervention group ( $p=$ 0.916), and no significant differences decreased IL-31 serum levels before and after 6 weeks in the control group ( $p=0.954)$. Unpaired t-test showed no significant difference between the mean IL-31 serum levels of the intervention group and the control group after 6 weeks of action ( $p=0.931)$.

Table 2: IL-31 serum levels before and after 6 weeks

\begin{tabular}{lrll}
\hline Group & IL-31 serum levels $(\mathrm{pg} / \mathrm{ml})($ mean $\pm \mathrm{SD})$ & $\mathrm{p}$ & \\
\cline { 3 - 4 } & & Within & Between \\
\hline Intervention & & & \\
$\quad$ Before & $35.88 \pm 39.79$ & 0.916 & 0.931 \\
$\quad$ After & $35.32 \pm 32.92$ & & \\
Control & & & \\
$\quad$ Before & $36.27 \pm 29.31$ & 0.954 & \\
$\quad$ After & $35.99 \pm 25.87$ & & \\
\hline IL: Interleukin, SD: Standard deviation. &
\end{tabular}

The Mann-Whitney test further showed a significant difference a decrease in duration, degree, disability, and distribution of the pruritus before and after 6 weeks (Table 3 ).

Table 3: Dimensional of the pruritus before and after 6 weeks

\begin{tabular}{|c|c|c|c|c|c|c|}
\hline \multirow{2}{*}{$\begin{array}{l}\text { Dimensional of the } \\
\text { pruritus median (min-max) }\end{array}$} & \multicolumn{2}{|l|}{ Before } & \multirow[t]{2}{*}{$p$} & \multicolumn{2}{|l|}{ After } & \multirow[t]{2}{*}{$\mathrm{p}$} \\
\hline & Acupuncture & Placebo & & Acupuncture & Placebo & \\
\hline Duration & $1(1-5)$ & $2(1-5)$ & 0.502 & $1(1-5)$ & $1.5(1-5)$ & 0.034 \\
\hline Degree & $4(2-5)$ & $4(2-5)$ & 0.792 & $2(1-4)$ & $3(1-5)$ & 0.020 \\
\hline Direction & $4(2-5)$ & $4(1-5)$ & 0.064 & $3(2-4)$ & $3(1-5)$ & 0.232 \\
\hline Disability & $4(1-5)$ & $4(2-5)$ & 0.496 & $2(1-4)$ & $3(1-5)$ & 0.048 \\
\hline Distribution & $3(1-5)$ & $3(1-5)$ & 0.383 & $2(1-4)$ & $3(1-5)$ & 0.038 \\
\hline
\end{tabular}

Results of the Spearman's rho correlation test showed that there was no correlation between IL-31 serum levels and dimensional of the pruritus after 6 weeks of acupuncture in LI11 Quchi (Table 4).

Table 4: Correlation between IL-31 and dimensional of the pruritus after 6 weeks

\begin{tabular}{lll}
\hline Correlation IL-31-dimensional of the pruritus & $\mathrm{r}$ & $\mathrm{p}$ \\
\hline Duration & -0.032 & 0.868 \\
Degree & -0.124 & 0.515 \\
Direction & 0.177 & 0.350 \\
Disability & 0.172 & 0.362 \\
Distribution & -0.136 & 0.474 \\
\hline
\end{tabular}

\section{Discussion}

In this part, the acupuncture in LI11 Quchi effects on the IL-31 serum levels (anti-inflammatory cytokines) and other factors are discussed. Data found that impacts of IL-31 serum level were not significant; so these results are consistent with the previously findings of the research Santos et al. [14]. It shows the effects of acupuncture on inflammation by lowering the levels of pro-inflammatory cytokines without affecting the levels of anti-inflammatory cytokines [14]. Several studies have also reported the role of IL-31 as pruritogenic [22], [23], [24], [25], [26], [27], [28]. IL-31 serum levels were significantly higher in HD patients 
with symptoms of pruritus, and there was a positive relationship response between IL-31 serum levels and pruritic intensity [6]. Besides that, IL-31 plays an essential role in the pathogenesis of atopic dermatitis. Severe pruritus is the main symptom of atopic dermatitis, and IL-31 contributes to this pruritus through activation of IL-31R $\alpha$ in sensory nerve cells [23]. Some studies, stimulation with acupuncture, pressure, moxa, or cold application at the acupuncture point LI11 Quchi showed a reduction in pruritic sensation in atopic dermatitis [29]. Expression of IL-31 is not only increased in patients with atopic dermatitis but also people with allergic contact dermatitis [30]. In patients with skin lymphoma T cells, serum levels of IL-31 increased compared to controls (healthy people). IL-31 plays a role in causing pruritus in patients with chronic spontaneous urticaria [26], and this condition, IL-31 serum levels increase significantly compared with non-topics, although it is substantially lower than atopic dermatitis patients [27], it shows the positive results for pruritus, the mechanism of the antipruritic effects of acupuncture is still unknown. It was believed that the antipruritic effects of acupuncture were caused by peripheral and central mechanism [29].

Pruritus is the most common complication in patients with hemodialysis, but there is limited knowledge of the patient's overall symptom experience. Results of this study identified the impact of acupuncture on LI11 in everyday life on the frequency of symptoms. After 6 weeks of acupuncture in LI11 Quchi, the findings of this study were a significant decrease in duration, degree, disability, and distribution of the pruritus.

Several hypotheses are suggested for the acupuncture treatment mechanisms. The impact on the endogenous opioid system is one of the most popular hypotheses. The endogenous opioid system's selective action plays a significant role in pruritus management. Narita et al. reported that nalfurafine had positive impacts on pruritus, while $\mu$-opioid antagonist (naltrexone) did not alleviate pruritus in patients with hemodialysis [31]. Histamine and mast cells are related to another hypothesis because histamine influences many cellular reactions, including allergy, inflammation, and gastric acid secretion. When the body is exposed to physical and chemical irritations or allergic reactions, mast cells are degranulated, resulting in histamine release and subsequent biological impacts. Furthermore, intradermal iontophoresis or injection of histamine triggered itching after a characteristic latency of up to $1 \mathrm{~min}$ [32].

The molecular mechanism of interaction between the nervous system and the immune system plays a role in the improvement of pruritus. Two-way neuroimmune communication marks the nervous system as an essential part of the immune system in the mechanism of inflammation including the role of the Vagus nerve as a physiological regulator of immune and inflammatory functions [33].

The data obtained indicate that the correlation of IL-31 serum levels with the dimension of the pruritus was not significant after 6 weeks of acupuncture in LI11 Quchi. Several factors that might influence the effect of acupuncture in LI11 Quchi on IL-31 serum levels associated with changes in dimension of the pruritus, such as: (1) The effect-dose relationship on acupuncture consists of three main factors affecting the effects of acupuncture: Depth, intensity, and time interval [34]. In this study, the extent of $1-1.5 \mathrm{~cm}$ acupuncture needle insertion, manual stimulation for $60 \mathrm{~min}$ at intervals of 2 times a week affected the change in IL-31 serum levels was not significant, (2) acupuncture point combination. The study proves acupuncture in LI11 Quchi along with other acupuncture points, significantly affects the improvement of pruritus. A significant decrease in pruritus after acupuncture in LI11 Quchi, SP6 Sanyinjiao, SP10 Xuehai, LR3 Taichong, and LI4 Hegu [35]. There may be some possible limitations in this study. The first is the masking practitioners and subjects are done to minimize the possibility of bias. Blind to practitioners of acupuncture and subjects was challenging to place on study design as an alternative to a double-blind standard study. The second limitation concerns the given the lack of rigorous research to date and the fact that this study was a single central RCT, further multicenter pragmatic testing was needed to evaluate the efficacy of the acupuncture in LI11 Quchi on IL-31 serum level in pruritic patients undergoing hemodialysis to confirm the generalization of these findings in other settings.

\section{Conclusion}

The effect of acupuncture on reducing dimensions of the pruritus not related to IL-31 serum levels. The action mechanism identification of acupuncture may minimize pruritus considerably; it enhances the knowledge of the impacts of acupuncture on reducing pruritus in hemodialysis patients.

Data interpretation found that the effects of acupuncture did not affect IL-31 serum levels but did affect the decrease in pruritus, and no association of IL-31 serum levels with pruritus was found - the effect of acupuncture on reducing pruritus not related to serum levels of IL-31. Identifying the mechanism of action of acupuncture to minimize pruritus significantly improves the understanding of the effects of acupuncture on decreasing pruritus in patients undergoing hemodialysis.

\section{Acknowledgments}

Doctors supported this research, nurses, and laboratory assistants on Hemodialysis Unit, Kidney 
and Hypertension Installation and Department Clinical Pathology H. Adam Malik General Hospital/Faculty of Medicine, Universitas Sumatera Utara, Medan, Indonesia.

\section{References}

1. Hu X, Sang $Y$, Yang $M$, Chen $X$, Tang W. Prevalence of chronic kidney disease-associated pruritus among adult dialysis patients. Medicine. 2018;97(21):e10633. https://doi. org/10.1097/md.0000000000010633

PMid:29794739

2. Mathur VS, Lindberg J, Germain M, Block G, Tumlin J, Smith M, et al. A longitudinal study of uremic pruritus in hemodialysis patients. Clin J Am Soc Nephrol. 2010;5(8):1410-9. https://doi. org/10.2215/cjn.00100110

\section{PMid:20558560}

3. Mollanazar NK, Koch SD, Yosipovitch G. Epidemiology of chronic pruritus: Where have we been and where are we going? Curr Dermatol Rep 2015;4(1):20-9. https://doi.org/10.1007/ s13671-014-0093-y

4. Ständer S, Stumpf A, Osada N, Wilp S, Chatzigeorgakidis E, Pfleiderer B. Gender differences in chronic pruritus: Women present different morbidity, more scratch lesions and higher burden. $\mathrm{Br} J$ Dermatol. 2013;168(6):1273-80. https://doi. org/10.1111/bjd.12267

PMid:23387396

5. Elman S, Hynan LS, Gabriel V, Mayo MJ. The 5-D itch scale: A new measure of pruritus. Br J Dermatol. 2010;162(3):587-93. https://doi.org/10.1111/j.1365-2133.2009.09586.x PMid:19995367

6. Ko MJ, Sen PY, Chen HY, Hsu SP, Pai MF, Yang JY, et al. Interleukin-31 is associated with uremic pruritus in patients receiving hemodialysis. JAmAcad Dermatol. 2014;71(6):1151-9. e1. https://doi.org/10.1016/j.jaad.2014.08.004 PMid:25270263

7. Mettang M, Weisshaar E. Pruritus: Control of itch in patients undergoing dialysis. Skin Ther Lett. 2010;15(2):1-5. PMid:20361169

8. Suzuki $\mathrm{H}$, Omata $\mathrm{H}$, Kumagai $\mathrm{H}$. Recent advances in treatment for uremic pruritus. Open J Nephrol. 2015;5(1):1-13. https://doi. org/10.4236/ojneph.2015.51001

9. Tarikci N, Kocatürk E, Güngör Ş, Topal IO, Can PÜ, Singer R. Pruritus in systemic diseases: A review of etiological factors and new treatment modalities. Sci World J. 2015;2015:803752. https://doi.org/10.1155/2015/803752 PMid:26240837

10. Gui J, Xiong F, Li J, Huang G. Effects of acupuncture on Th1, Th2 cytokines in rats of implantation failure. Evid Based Complement Altern Med. 2012;2012:893023. PMid:22315633

11. Wang Z, Chen T, Long M, Chen L, Wang L, Yin N, et al. Electroacupuncture at acupoint ST36 ameliorates inflammation and regulates Th1/Th2 balance in delayed-type hypersensitivity. Inflammation 2017;40(2):422-34. https://doi.org/10.1007/ s10753-016-0487-z PMid:27966183

12. Zijlstra FJ, van den Berg-de Lange I, Huygen FJ, Klein J. Anti-inflammatory actions of acupuncture. Mediator Inflamm. 2003;12(2);59-69. https://doi. org/10.1080/0962935031000114943

PMid:12775355

13. da Silva MD, Bobinski F, Sato KL, Kolker SJ, Sluka KA, Santos AR. IL-10 Cytokine released from M2 macrophages is crucial for analgesic and anti-inflammatory effects of acupuncture in a model of inflammatory muscle pain. Mol Neurobiol. 2014;51(1):19-31. https://doi.org/10.1007/s12035-014-8790-x PMid:24961568

14. Santos AR., Da Silva MD, Guginski G, De Paula Werner MF Baggio $\mathrm{CH}$, Marcon R. Involvement of interleukin-10 in the antiinflammatory effect of Sanyinjiao (SP6) acupuncture in a mouse model of peritonitis. Evid Based Complement Altern Med. 2011;2011:217946. https://doi.org/10.1093/ecam/neq036 PMid:21799673

15. Kim SK, Bae H. Acupuncture and immune modulation. Auton Neurosci. 2010;157(1-2):38-41.

PMid:20399151

16. Chou CY, Wen CY, Kao MT, Huang CC. Acupuncture in haemodialysis patients at the Quchi (LI11) acupoint for refractory uraemic pruritus. Nephrol Dial Transplant. 2005;20(9):1912-5. https://doi.org/10.1093/ndt/gfh955

PMid:15985509

17. Phan FA, Srilestari A, Mihardja H, Marbun MB. Effects of acupuncture on uremic pruritus in patients undergoing hemodialysis. J Phys. 2018;2018:062049. https://doi. org/10.1088/1742-6596/1073/6/062049

18. MacPherson H, Altman DG, Hammerschlag $\mathrm{R}$, Youping L, Taixiang W, White A, Moher D. Revised Standards for reporting interventions inclinical trials ofacupuncture(STRICTA): Extending the CONSORT statement. J Evid Based Med 2010;3(3):140-55. https://doi.org/10.1111/j.1756-5391.2010.01086.x

19. Franz F, Erdfelder E, Lang AG, Buchner A. G*Power 3.1 (manual): A flexible statistical power analysis program for the social, behavioral, and biomedical sciences. Behav Res Methods. 2007;39(2):175-91. https://doi.org/10.3758/ bf03193146

PMid:17695343

20. Wulandani MP, Dachlan AS, Yusharyahya SN. Validity and reliability of 5-D itch scale in Indonesian language on adult and geriatric patient at Dr Cipto mangunkusumo hospital. Adv Sci Lett. 2018;24:6994-8. https://doi.org/10.1166/asl.2018.12910

21. Kim J, Oh HJ, Yoon SP. A cadaveric study of needle insertion at LI11. Acupunct Med. 2015;33(6):497-9. https://doi.org/10.1136/ acupmed-2015-010980

22. Ezzat MH, Hasan ZE, Shaheen KY. Serum measurement of interleukin-31 (IL-31) in paediatric atopic dermatitis: Elevated levels correlate with severity scoring. J Eur Acad Dermatol Venereol. 2011;25(3):334-9. https://doi. org/10.1111/j.1468-3083.2010.03794.x PMid:21294778

23. Kasraie S, Niebuhr M, Werfel T. Interleukin (IL)-31 induces pro-inflammatory cytokines in human monocytes and macrophages following stimulation with staphylococcal exotoxins. Allergy. 2010;65(6):712-21. https://doi. org/10.1111/j.1398-9995.2009.02255.x PMid:19889120

24. Narbutt J, Olejniczak I, Sobolewska-Sztychny D, SysaJedrzejowska A, Słowik-Kwiatkowska I, Hawro T, et al. Narrow band ultraviolet B irradiations cause alteration in interleukin-31 serum level in psoriatic patients. Arch Dermatol Res. 2013;305(3):191-5. https://doi.org/10.1007/s00403-012-1293-6 PMid:23108364

25. Nobbe S, Dziunycz P, Mühleisen B, Bilsborough J, Dillon SR, French LE, et al. IL-31 expression by inflammatory cells is preferentially elevated in atopic dermatitis. 
Acta Dermatol Venereol. 2012;92(1):24-8. https://doi. org/10.2340/00015555-1191

PMid:22041865

26. Ohmatsu H, Sugaya M, Suga H, Morimura S, Miyagaki T, Kai H, et al. Serum IL-31 levels are increased in patients with cutaneous T-cell lymphoma. Acta Dermatol Venereol. 2012;92(3):282-3. https://doi.org/10.2340/00015555-1345

PMid:22456907

27. Raap U, Wieczorek D, Gehring M, Pauls I, Ständer S, Kapp A, Wedi B. Increased levels of serum IL-31 in chronic spontaneous urticaria. Exp Dermatol. 2010;19(5):464-6. https://doi. org/10.1111/j.1600-0625.2010.01067.x PMid:20163453

28. Singer EM, Shin DB, Nattkemper LA, Benoit BM, Klein RS, Didigu CA, et al. IL-31 is produced by the malignant T-cell population in cutaneous T-cell lymphoma and correlates with CTCL pruritus. J Investig Dermatol. 2013;133(12):2783-5. https://doi.org/10.1038/jid.2013.227

PMid:23698099

29. Jung HJ, Park SY. Combination effects of capsicum plaster at the Korean hand acupuncture points k-d2 with prophylactic antiemetic on postoperative nausea and vomiting after gynecologic laparoscopy. J Korean Acad Nurs. 2013;43(2):21524. https://doi.org/10.4040/jkan.2013.43.2.215

PMid:23703599
30. Neis MM, Peters B, Dreuw A, Wenzel J, Bieber T, Mauch C, et al. Enhanced expression levels of IL-31 correlate with IL-4 and IL-13 in atopic and allergic contact dermatitis. J Allergy Clin Immunol. 2006;118(4):930-7. https://doi.org/10.1016/j. jaci.2006.07.015

PMid:17030248

31. Narita I, Iguchi S, Omori K, Gejyo F. Uremic pruritus in chronic hemodialysis patients. J Nephrol. 2008;21(2):161-5.

PMid:18446709

32. Kremer AE, Feramisco J, Reeh PW, Beuers U, Elferink RPJ. Receptors, cells and circuits involved in pruritus of systemic disorders. Biochim Biophys Acta. 2014;1842(7);869-92. https:// doi.org/10.1016/j.bbadis.2014.02.007

PMid:24568861

33. Pavlov VA, Tracey KJ. Neural circuitry and immunity. Immuno Res. 2015;63(1-3):38-57.

PMid:26512000

34. Zhao L, Chen J, Liu CZ, Li Y, Cai DJ, Tang Y, et al. A review of acupoint specificity research in China: Status Quo and prospects. Biophys Basis Merid Acupoint Funct 2012;2012:543943. https:// doi.org/10.1155/2012/543943

35. NahidiY, Badiee S, Torabi S, Shaye ZA, Nazemian F. Acupuncture effect on pruritus in hemodialysis patients: A randomized clinical trial. Iran Red Crescent Med J. 2018;20:65521. https://doi. org/10.5812/ircmj.65521 